\title{
Materialismo, realismo y prosaísmo en la joven poesía latinoamericana de los años noventa
}

\author{
Materialism, Realism and Prosaism in the Young \\ Latin American Poetry of the Nineties \\ Materialismo, realismo e prosaísmo na poesia jovem \\ latino-americana dos anos noventa
}

\section{Gustavo Guerrero}

UNIVERSITÉ DE CERGY-PONTOISE/INSTITUT D'ÉTUdES POLITIQUES DE SAINT-GERMAIN-EN-

LAYE, FRANCIA

Profesor de literaturas hispánicas modernas en Université de Cergy-

Pontoise y de historia cultural en el Instituto de Estudios Políticos de

Saint-Germain-en-Laye, Francia. Doctor en Historia y Teoría Literaria,

École des Hautes Études en Sciences Sociales (EHESS), París. Ha

publicado los libros de ensayo La estrategia neobarroca (Ediciones

del Mall, 1987), Itinerarios (Monte Ávila, 1997), Teorías de la lírica

(Fondo de Cultura Económica, 1998) y La religión del vacío y otros

ensayos (Fondo de Cultura Económica, 2002), obra finalista del Premio

Bartolomé March de Crítica Literaria, en 2003. Premio Anagrama de

Ensayo por Historia de un encargo: La catira de Camilo fosé Cela

(Anagrama, 2008). Correo electrónico: gustavo.guerrero-cergy.fr

Artículo de reflexión

Documento accesible en línea desde la siguiente dirección: http://revistas.javeriana.edu.co 


\section{Resumen}

El objetivo de este es examinar las particularidades que presenta el tópico de las relaciones entre las palabras y las cosas en algunos jóvenes poetas latinoamericanos que empiezan a darse a conocer en los años noventa del siglo pasado. Todos los que aquí se estudian dan cuenta del cambio cultural que se produce durante esa década a través de una poética materialista, realista y prosaica, cuyo fuerte acento crítico cuestiona los rumbos de unas sociedades en las que el neoliberalismo y los simulacros mediáticos gobiernan un presente que se vuelve perpetuo y secuestra la idea de porvenir.

Palabras clave: poesía; América Latina; cultura material; siglo XX; años noventa

\section{Abstract}

This short article analyzes the topos of the relationship between words and things in a selected corpus of young Latin American poets who start publishing in the late nineties. The poets studied in this essay allow us to read the decade's cultural transformations through the materialistic, realistic and prosaic poetics they put into practice. Their poetry takes a strong critical orientation that denounces societies in which neoliberalism and media rule, as well as a present that has become perpetual and has hijacked the idea of future.

Keywords: poetry; Latin America; material culture; XX century; the nineties

\section{Resumo}

O objetivo deste é rever as particularidades apresentadas pelo tópico das relações entre as palavras e as coisas em alguns poetas jovens latino-americanos que começam a se dar a conhecer na década de noventa do século passado. Todos os aqui estudados dão conta da mudança cultural produzida durante tal década através de uma poética materialista, realista e prosaica, cujo forte teor crítico põe em questão os rumos de umas sociedades nas que o neoliberalismo e os simulacros mediáticos governam um presente que se torna perpetuo e sequestra a ideia de porvir.

Palavras-chave: poesia; América Latina; cultura material; século $\mathrm{XX}$; anos noventa

\section{Cómo citar este artículo:}

Guerrero, Gustavo. "Materialismo, realismo y prosaísmo en la joven poesía latinoamericana de los años noventa". Cuadernos de Literatura 20.40 (2016): 394-410. http://dx.doi.org/10.11144/Javeriana.cl20-40.mrjp 
EMPIEZO RINDIÉNDOME ANTE una evidencia: la poesía no ha esperado hasta el advenimiento de un campo de estudios de la cultura material para entablar una relación intensa, variada y continua con los objetos que las sociedades humanas producen en distintas épocas y geografías. Entre los mapas del gabinete de curiosidades barrocas y las porcelanas de las exquisitas colecciones modernistas, pasando por el paraguas y la máquina de coser de Lautréamont, o proyectándose hasta las famosas odas a la papa de Pablo Neruda, un extenso capítulo de la historia de la poesía moderna narra los avatares de la trama que los poetas han ido tejiendo y destejiendo entre las palabras y las cosas. Sus descripciones no solo constituyen, en muchos casos, un testimonio para el análisis de los objetos más característicos de una cultura dada, sino que arrojan además una luz indispensable a la hora de entender la fábrica de las subjetividades y la forja de los imaginarios que inciden en la evolución de las ideologías, los horizontes de expectativas y las estructuras de sentimiento a través del tiempo. Los poetas y la poesía nos recuerdan así, insistentemente, que las cosas existen de diversas maneras en las representaciones que el lenguaje ha ido haciendo de ellas y que tratan de dar cuenta de cómo han sido vistas, tocadas, escuchadas, confeccionadas o destruidas en diferentes ámbitos y por diferentes sujetos. Aunque solo dispongamos de versiones parciales, ese capítulo o esa crónica de nuestra aprehensión material del mundo compendia, hoy por hoy, una de las mayores aventuras del quehacer poético moderno. A saber: el afán de hacerse un lugar más o menos visible, más o menos explícito, en los confines de una porosa frontera donde se encuentran la construcción literaria de un universo simbólico con una antropología y una epistemología de lo sensible.

Quiero dedicar estas breves líneas a un momento de esa larga crónica - los años noventa del pasado siglo - y a cuatro o cinco jóvenes poetas que, en distintos países de América Latina, comparten la necesidad de plantear o, mejor, de replantear, la problemática de las relaciones entre las palabras y las cosas. De entrada, he de advertir que concibo este ejercicio como un modesto ensayo de interpretación que ni aspira a la exhaustividad ni a la fuerza conclusiva de una monografía o un estudio propiamente dicho. Lo que me interesa es, simple y básicamente, señalar una tendencia en la poesía de fines del siglo XX, que reúne a algunas figuras dispares procedentes de tradiciones nacionales diferentes, pero que, gracias a sus inquietudes comunes, acaban adquiriendo un cierto aire de familia. Acaso por ello mismo estos poetas nos invitan a relativizar el peso de los contextos locales, sobre todo en unos años en los que la revolución tecnológica y comunicativa acelera vertiginosamente la circulación de textos e informaciones a todo lo largo del continente. 
Hablar de la poesía de los años noventa implica varios asuntos, al mismo tiempo que exige algunas explicaciones. Comprende asumir una periodización por décadas que es ya bastante común en la crítica literaria y académica; pero que, al igual que su predecesora, la vieja periodización por generaciones, acarrea no pocos problemas y muchos malentendidos. Y es que no solo trae infuso el falso supuesto de una correspondencia entre la temporalidad de los fenómenos literarios y culturales y la segmentación cronológica que pretende organizarlos y describirlos. Además, y como corolario de ese primer supuesto, introduce subrepticiamente una cierta idea de la modernidad como sucesión de rupturas, lo que a menudo obliga a los que trabajan con este tipo de periodización a buscar afanosamente los signos del cambio que justifique o motive la novedad de aquello que analizan. De ahí que no sean pocos los trabajos sobre la poesía de las décadas de los setenta, de los ochenta o de los noventa que acaben pasando por alto continuidades que se extienden sobre el eje de una temporalidad más larga o que eleven a la condición de rasgos diferenciales a poéticas, formas y prácticas escriturales de las que existen ejemplos anteriores entre las vanguardias o, aún más lejos, en la poesía barroca. Incurrir en este tipo de error no solo engendra espejismos históricos y arroja una sombra de olvido sobre una parte del pasado, sino que, además, escamotea el debate esencial sobre el estatuto de la novedad misma que recorre el fin del siglo XX (Huyssen 26). Por otra parte, hablar de la poesía de los años noventa implica, asimismo, postular un principio de unidad justo en una década marcada por la crisis de los consensos que habían existido hasta entonces en torno al concepto de poesía como género literario y fenómeno cultural. No aludo solamente a los distintos debates entre tendencias opuestas a ambos lados del Atlántico (neobarrocos contra objetivistas, poetas de la experiencia contra poetas metafísicos). Aludo también, y sobre todo, a la diversificación transmedial que acompaña la aparición nuevos formatos orales, gráficos y audiovisuales vinculados con la televisión, el mundo del arte o la música popular (Mora 14-28). Esta diversificación, que la red va a potenciar a partir de 1993, afecta incluso a la noción misma de poemario o libro de poemas, ya que su formato editorial tiende a transformarse en busca de una singularidad pronunciada que marque distancias con el pasado o que se corresponda mejor con los modos de circulación alternativos que lo separan ahora de los circuitos de distribución tradicionales (Mazoni y Selci 258-268). Todo esto, creo, debería obligarnos a ser extremadamente cautos cuando empleamos la expresión poesía de los noventa y acaso a preferir siempre, en el área latinoamericana, el plural poesías de los noventa.

Hechas estas advertencias, me acerco a los ejercicios materiales de estos poetas, tratando de entender lo peculiar que pueda haber en ellos, si acaso no lo nuevo, así como las maneras en que se relacionan con varios contextos de ese 
agitado y particular decenio, porque los años noventa son una década que ha ido adquiriendo, en el campo de la historia actual, un perfil cada vez más definido y significativo. Recordemos que, para especialistas como François Hartog, se trata de los años que señalan nuestro ingreso en este tiempo contemporáneo que aún habitamos, tras la caída del muro de Berlín, el final de la Guerra Fría y la entronización de un nuevo régimen de historicidad caracterizado por la hegemonía del presente. Al prologar las actas de un simposio que tuvo lugar en la Universidad de Yale, en 1994, Josefina Ludmer apelaba al paralelismo entre "fin de siglo" $y$ "fin de ciclo" para describir el clima de aquel decenio tan coloreado por una idea de transición y/o de fase terminal, entre terrores apocalípticos y saltos modernizadores (8). Lo cierto es que son los años de un balance crítico que no solo atañe a las utopías históricas del siglo XX, sino también a las estéticas que las acompañaron o las adversaron, tanto dentro del campo del realismo como del idealismo. Por un lado, se asiste así a la descomposición final del viejo legado romántico y de la idea de la poesía como práctica substitutiva de la religión o la filosofía, destinada a aportar una revelación de verdades trascendentes; por otro, se revisa la herencia vanguardista y comprometida del coloquialismo de los años sesenta y setenta, y se produce un cuestionamiento de las formas del realismo, socialista o no, con que se quiso apoyar los proyectos de emancipación política (Guerrero 11-33).

En pocas palabras, digamos que años los noventa son el escenario de un naufragio estético general que pone a las nuevas generaciones en una situación inédita, ya que las obliga a presentarse, alternativa o simultáneamente, como sobrevivientes de una catástrofe o como pioneras de un mundo nuevo. En ambos casos, aparecen flotando en un mar abierto donde el mapa de la tradición es a menudo de tan poca ayuda que ni siquiera el parricidio o la ruptura parecen pertinentes. Y si no vale repetir esos gestos es porque la aceleración histórica ha sido tan brutal que la relación entre las generaciones tiende a disolverse $\mathrm{o}$ a hacerse más laxa, y deja a los recién llegados en una extraña condición de orfandad, sin referencias ni filiaciones claras (Porrúa 86-87). Entiéndaseme bien: las bibliotecas y los cánones poéticos siguen de pie, qué duda cabe; pero lo que marca a muchos jóvenes poetas de la década no está tanto (o solo) en ellos, como (y también) en una experiencia de la extranjería y la soledad que afina sensibilidades y señala entonces un nuevo punto de partida. A mi modo de ver, la problematización y el replanteamiento de la relación entre las palabras y las cosas en la poesía de la década de los noventa es uno de los escenarios o de los tópicos a través de cuales se va enunciar y a hacer visible esta circunstancia. Una vez más, como tantas otras en el pasado, los objetos fungen de instrumentos para revelar imaginarios y subjetividades; pero los imaginarios y las subjetividades que revelan corresponden a 
un contexto específico y permiten comprender y valorar el particular espíritu de un lugar y una época:

\section{A mitad de la noche}

Me levanto a mitad de la noche con mucha sed.

Mi viejo duerme, mis hermanos duermen.

Estoy desnudo en el medio del patio

y tengo la sensación de que las cosas no me reconocen.

Parece que detrás de mí nada hubiese concluido.

Pero estoy otra vez en el lugar donde nací.

El viaje del salmón

en una época dura.

Pienso esto y abro la heladera:

un poco de luz desde las cosas

que se mantienen frías.

(Casas, El salmón 23)

Cómo se llama eso que cuelga de la pared, cómo se llama eso que cubre la lámpara.

Rodeado de cosas sin nombre a mí también me hubiera gustado empezar esto con: de noche junto al fuego pero acá no hay, salvo en potencia, fuego y eso que se divisa, una oscuridad baldía sobre nosotros, a duras penas puede ser llamada noche, nada hace suponer el final de la transmisión nocturna que ahora termina y deja la pantalla nevada trasladando a la penumbra del pasillo la oscilación de un aire gris que no provoca ninguna emoción salvo en las cosas.

(Gambarotta 8)

\section{Paisaje con salvoconducto}

no es obra mía este pedazo cuadrado de tierra ejida, no hay nada en el lote de objetos tirados por el suelo 
que me deba su vida o su olvido,

porque yo llegué tarde a la repartición de la magia

capaz de hacer aparecer

con escasas palabras

una cosa rotunda,

frágil,

inmortal;

a la hora de sellar mi entrada aquí

ya la basura se amontonaba en los baldíos;

¿qué podría yo agregar

que no fuera

un poco de celos por el milagro

de imaginar con algo de concentración un universo

deteriorado y vivo?

porque ahora estoy parado en este trozo cuadrado de tierra

extranjera.

(Moreno Villamediana, Cantares 16)

Dos argentinos, Fabián Casas y Martín Gambarotta, y un venezolano, Luis Moreno Villamediana, ponen así en escena un modo conflictivo de relacionarse con los objetos que les permite describir, de forma más o menos explícita, el lugar de enunciación desde el cual habla su poesía en el fin de siglo. "Estoy desnudo en el medio del patio / y tengo la sensación de que las cosas no me reconocen...", dice Casas; "cómo se llama eso que cuelga de la pared / cómo se llama eso que cubre la lámpara / Rodeado de cosas sin nombre a mí también me habría gustado empezar esto / con: de noche junto al fuego / pero acá / no hay, salvo en potencia, fuego...", replica Gambarotta. Moreno Villamediana concluye: "no hay nada en el lote de objetos tirados por el suelo / que me deba su vida o su olvido / porque yo llegué tarde a la repartición de la magia / capaz de hacer aparecer / con escasas palabras / una cosa rotunda, frágil, inmortal...". Los antiguos pactos entre lenguaje y mundo material se han roto. No se puede menos que comprobar que en ninguno de nuestros tres poetas subsiste traza alguna del optimismo cognitivo que alimentaba la poética de Ponge o, más cerca de nosotros, la festiva presencia de los objetos en los versos de un Eliseo Diego. Por el contrario, el silencio de las cosas es ahora el asunto común que les permite hacer un balance de sus poderes perdidos ante un mundo que se ha vuelto indiferente, distante y ajeno. Lo que los reúne en aquella coyuntura es la impotencia, es un sentir de lo íngrimo y un materialismo que representa, ante todo, el recurso para señalar el final de la 
agenda idealista y romántica. Porque no estamos hablando de un materialismo científico ni de un materialismo histórico, nada que encierre la promesa de un futuro alternativo. Como bien ha indicado Daniel Freidemberg al describir el tránsito entre el primer objetivismo argentino y la poesía de los años noventa, hemos pasado de una pregunta — “esto es lo que hay?" - a una aseveración _-"esto es lo que hay" -; digamos que, para los nuevos poetas, la interrogante se convierte en simple y dura constatación (151). Su materialismo juvenil, vulgar y casi sanchopancesco tiene un correlato estético en un realismo desenfadado y proteico que puede pintarnos con los objetos paisajes nocturnos y devastados, como acabamos de verlo; pero que puede servirse asimismo de la relación entre los objetos y el lenguaje como el tema explícito de una suerte de ejercicios irónicos, bastante socarrones y esencialmente metapoéticos. Revertido, el tema del "silencio de las cosas" se convierte de esta suerte en el del "ruido de las cosas" o, aun, el del "escándalo de las cosas".

\section{Un saunche tiene derecho a voz y voto}

ya que eso que voy a comer y por gusto llamo "pan" no me habla, ya que eso desgraciadamente delante de mí se hace el mudo,

voy a volverme un dios y a concentrarme

hasta un punto tal

que pasando por encima de la autoridad de todos

los ingredientes

y dejando de lado su aspereza,

el color dorado de su concha,

la presencia constante del queso,

lo voy a hacer hablar como si de mí mismo

se tratara

y hacerle decir "señores,

déjenme en paz,

de muerte natural quiero irme al infierno.

(Moreno Villamediana, Manual 40 )

\section{Cosas que hace tu bata blanca}

1.

Durante meses

colgada en el baño

como vos la dejaste,

fosforescente en la noche.

2. 


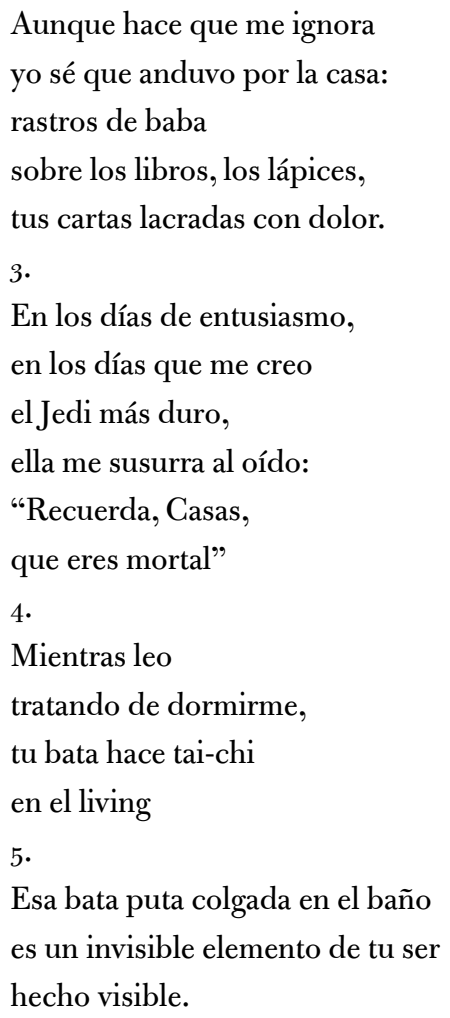

(Casas, Oda 23)

Riendo y llorando con los objetos, con humor e ironía, Casas y Moreno Villamediana dan cuenta así de una cierta situación de la poesía en el fin de siglo y sientan un testimonio de las estrategias que siguen entonces algunos jóvenes poetas para posicionarse dentro de un campo literario y cultural donde se asiste, a la par, a un trastocamiento de los modelos comunicativos y a una demanda cada vez más urgente de discursos realistas: lo uno y lo otro, lo uno por lo otro. Efectivamente, tal y como ha señalado Beatriz Jaguaribe: "Una de las principales consecuencias de la globalización cultural fue la naturalización de los códigos del realismo como formas de aprensión de lo cotidiano" (16). La revolución tecnológica que hace posible la televisión por cable y satélite, la multiplicación del número de cadenas y la sobreproducción de imágenes - un proceso que se ve potenciado por la invención y la difusión de la red - crea las condiciones de esta incorporación del realismo a nuestra vivencia diaria y a nuestras formas de racionalización y aprensión del mundo a un nivel planetario. Pero dicho fenómeno no puede ni debe separarse de una aceleración sin precedentes de otras dos tendencias que vienen de lejos y que 
se manifiestan de un modo novedoso y extremo: por un lado, la relativización de las fronteras entre ficción y no ficción, que altera los pactos comunicativos tradicionales; por otro, la erosión final de las jerarquías heredadas entre sujetos, temas y modos de expresión, o, para decirlo con la terminología de Jacques Rancière, el colapso final del "régimen representativo de la literatura y el arte" con la subsecuente entronización de un régimen estético indiferente a cualquier tipo de correlación temática, enunciativa o expresiva (17-30). Los dos cambios definen los contornos de un paisaje cultural donde el simulacro mediático marca con una impronta espectacular nuestra fábrica de lo sensible a través del voyeurismo de los reality shows, a través de los pronunciados efectos de realidad que emplean los noticiarios más sensacionalistas o a través de la fiesta del impudor y la procacidad que pone en escena la telebasura. Los poetas de la década de los noventa tienen que vérselas con estos realismos y con un nuevo reino de la imagen que al transformarlo todo en simulacro - como había anticipado Baudrillard - le resta continuamente espesor político y ético a nuestra relación con las cosas, con los otros y con nosotros mismos. Baste recordar aquellas trasmisiones en vivo y en directo de la Primera Guerra del Golfo (1990-1991) que se compararon, con razón, a un videojuego. Ante tal trivialización, no han de faltar las tentativas por devolvernos la más intensa materialidad de las cosas, partiendo del espectáculo del propio cuerpo, como bien lo nota Foster y como puede leerse en la poesía de Moreno Villamediana.

\section{Lecciones quirúrgicas}

abrirse el pecho en medio de una plaza,

frente a los escolares,

frente a los jubilados y las amas

de casa, usar un hacha diestramente hurtada de la ferretería,

o en su defecto

una daga afilada, aunque vieja,

cortar la carne sin muestras de dolor,

empuñar un mazo y quebrarse los huesos

al tiempo que se escuchan los gritos

de la audiencia,

nada eso es,

sépanlo,

una salvajada,

ni siquiera la obligación de un rito;

me abro el pecho para mostrarles que dentro mío late

una espiga bermeja que no

bombea sangre, 
un tallo viscoso y pequeño que me pone en el cuerpo

una altura considerable,

un terraplén donde seguro crecerán otras frutas

de distinto color,

las cuales,

sépanlo también,

tendrán su valor en el mercado

como si fueran una res cualquiera,

una lonja no ya de Luis

sino de cierta especie mejor en extinción

que vive muchos años,

aunque por el pecho vuelto trozos oscuros

le entren moscas y gusanos mortales

(Moreno Villamediana, Cantares 80)

A los espectáculos de la realidad o, lo que es lo mismo, del "todo ficcional", como dice por entonces Marc Augé, Moreno Villamediana responde con el discurso prosaico de un cuerpo martirizado y abierto que, no sin ironía, pone en escena la extremosidad misma que lo alienta, hasta regodearse en lo morboso, como lo hacen muchos artistas del performance y la acción poética de los años noventa. Pienso, por ejemplo, en las intervenciones de las feministas mexicanas Lorena Wolffer y Ema Villanueva (Rodríguez Sosa) o en el trabajo a la vez objetualista y corporal del venezolano Carlos Zerpa (Suazo). Otros poetas de esta generación, que son contemporáneos de un cierto realismo sucio caribeño y latinoamericano, como el neobarroco dominicano León Félix Batista, van a jugar también a este juego del exceso y los límites que tiende a exaltar lo abyecto, lo atroz y lo repugnante en una suerte de sobrepujamiento destinado a subvertir, superar y cuestionar las construcciones sociales del cuerpo elaboradas por los realismos mediáticos (Félix Batista). Hay en ello indudablemente una reedición del gesto provocador de las vanguardias que no solo buscan dinamitar los códigos de la literatura y el arte, sino denunciar la normatividad perceptiva que gobierna, desde el poder, la fábrica de lo real. Pero en la década de los noventa la elaboración de tal realismo crítico, por lo que toca a la relación entre las palabras y las cosas, se enfrenta asimismo con la otra gran instancia mediadora que no convierte ya todo objeto en imagen, sino en mercancía. Se trata, evidentemente, del mercado, una maquinaria implacable cuya expansión, bajo la égida del neoliberalismo, pretende reencantar el planeta entero en aquel decenio gracias a las promesas de bienestar que trae consigo la globalización económica. Transformados en fascinantes fetiches por la publicidad, ya no solo el objeto, sino 
las marcas, se convierten en artículos de consumo e instrumentos para construir y afirmar identidades, sobre todo entre las generaciones más jóvenes. No en vano algunos críticos consideran que la presencia de las marcas constituye uno de los rasgos estilísticos más característicos de la poesía y la literatura del fin del siglo XX (Prieto y García Helder). Pero también es cierto que abundan los poemas donde el objeto no se muestra ya como mercancía y marca, sino como basura y desecho, a menudo abandonados en baldíos suburbanos erigidos en zonas de descarga, que son como las versiones invertida de los malls y comparten, con ellos, la misma condición de no lugares posmodernos. Varios poemas del objetivista argentino Daniel García Helder nos pintan estos nuevos escenarios del consumismo contemporáneo en los que, a lo largo del decenio, se van a ir interesando distintos artistas de Europa y América, como el fotógrafo y pintor brasileño Vik Muniz. Sus obras más conocidas muestran que el Trash Art, o el arte del reciclaje y la basura, no solo pone en escena las zonas de descarga, ese otro no lugar del neoliberalismo global, insisto, sino que también trae a la luz a los nuevos personajes excluidos de esta historia: el reducidor, el reciclador y, por supuesto, el mendigo.

\section{La balada de los reducidores}

Qué necesidad tenía nadie

en víspera de unos días que se trenzaban

como tallos en cuya ascensión

las hojas iban perdiendo peso y color

hasta casi flotar en la extrema transparencia, digo

qué necesidad tenía nadie de exhumar

de bajo una valla de piedras y detritos el verano.

El lomo de la rata entre los escombros se escabullía

y entre las ramas de la poda, un esqueleto de paraguas;

qué necesidad tenía nadie de mecer

con la punta del pie y riesgo para su vida

ese amasijo felpudo que en un cajón de frutas

entre papeles de diario y plumas pardas

blandía como unas pinzas de alacrán.

Y el viento en todo y siempre, el alambrado vencido

y junto a las vías muertas flores de sapo sobadas

por una luz rastrera, nubes cinerarias rezumando

agrio vino de orujo sobre casitas mampuestas

y la chatarra de los reducidores,

agujas y hojas que abrazan al tallo.

(García Helder, El guadual 27) 


\section{Hechos de los apóstoles}

en el principio,

los frascos de vidrio,

el abismo profundo de una lata,

se acumulaban vanamente

en el baldío

al calor del sol y al amparo

de las ortigas;

también la luz era entonces silvestre

e inventaba a las piedras

una suave textura, un envoltorio

decoroso y firme;

entonces yo,

el hombre,

un hombre,

cualquier hombre, dije

"vengan a mí

botellas, alambres, cuerdas y cristales,

yo soy la vida eterna",

y desde entonces las botellas,

los alambres, las cuerdas, los cristales

propagan mi doctrina,

$\mathrm{y}$ ahora todo hombre

y un hombre

y cualquier hombre

es miope,

torpe,

lento,

conmovido

y esconde en los despojos

su paraíso

(Moreno Villamediana, Cantares 79) 


\section{Investigación de mercado}

Una moneda, por amor de Dios, una moneda, que el dinero es el tema del mendigo y el mendigo es el tema de esta investigación: ¿ isi el mendigo tuviese dinero hablaría de asuntos menos mundanos? Pero he aquí un tintinear de monedas en el interior de una lata de sardinas sin sardinas. ¿Y las sardinas?

Baratas y nutritivas: ricas en hierro, vitamina A y fósforo. Un paladar exquisito diría que la sardina tiene un ligero dejo a: a) Metal sobado. b) Dinero rancio. c) Desayuno de mendigos. ¿Un mendigo es básicamente una alcancía?

(Fabre 25)

Si el mercado transforma todo objeto en mercancía, el consumo lo convierte en desecho. O, digámoslo de otra manera, a la manera de historiadores de la cultura y el arte: la fascinación del Pop Art en los años sesenta y setenta por los envases y las etiquetas, por la imagen frontal del cartel y el dispositivo publicitario que transfigura una cosa en producto comercial, deviene en la década de los noventa en una mirada a la otra cara del fenómeno: el consumo no ya en su fase de encantamiento, sino de desencantamiento, como una enloquecida máquina de generar basura y exclusión cuyo avance amenazador va ocupando cada vez más espacio en esos baldíos suburbanos que ahora fungen de cementerios e infiernos secretos de nuestras sociedades. Pido otra vez que se me entienda bien: la transfiguración del basurero en escenario no es una invención de la poesía y el arte de esa década. Todos recordamos aquella conmovedora escena final de Los olvidados (1950) de Luis Buñuel o aquel relato inolvidable de Julio Ramón Ribeyro, "Los gallinazos sin plumas" (1955). Pero lo que parece peculiar o nuevo en el fin de siglo es cómo el basurero, los desechos y sus protagonistas se vinculan a un discurso economicista, pragmático y utilitarista que incorpora críticamente la prédica neoliberal, como puede verse sobre todo en los poemas del venezolano Moreno Villamediana y del mexicano Luis Felipe Fabre. Ambos le hacen un lugar irónicamente a la triunfante religión del mercado: ver en los despojos un paraíso, o en un mendigo, una alcancía. Además, ambos nos recuerdan el cambio mayor que se ha producido durante la década por lo que respecta a los ritmos de producción y consumo. Jesús Martín Barbero supo resumirlo en una frase: "Vivimos en sociedades cuyos objetos duran cada vez menos, pues su acelerada obsolescencia es planificada por un sistema cuyo funcionamiento depende de que ella se cumpla". No es otra la clave de la expansión ilimitada por la que apuesta el neoliberalismo y que la 
globalización quiere llevar a una escala planetaria. Porque todo existe ahora para acabar no en un libro, sino en un basurero y rápidamente (incluso los libros). La poética de la basura en la poesía de los años noventa da cuenta de esta nueva situación del objeto que, en su devenir resto o desecho, plantea ahora una problemática distinta, alterando profundamente la vieja relación entre las palabras y las cosas. Y es que si extendemos un poco más la interpretación, acaso podamos advertir algo nuevo e inquietante: la sutil y soterrada humanización de los objetos que resulta de su obsolescencia tecnológicamente programada, una especie de muerte que de pronto los acerca a nuestra propia condición, cuando antes se esperaba de ellos que duraran y nos sobrevivieran, que fueran un testimonio de nuestra existencia individual y colectiva. El sistema económico que se impone a partir de los años noventa rompe así con un horizonte de expectativas milenario y reduce drásticamente, en nombre del crecimiento económico, las posibilidades de subsistencias de una cultura material de nuestra propia época.

A manera de conclusión, quisiera subrayar cómo algunos poetas latinoamericanos de los años noventa hacen visible esta especial coyuntura del fin de siglo a través de formas de subjetividad que le dan una tonalidad nueva a la relación entre las palabras y las cosas. Con ellas y a través de ellas, todos nos dicen que, efectivamente, no hay futuro porque hemos entrado en un nuevo régimen histórico dominado por un presente esencialmente presentista, para citar otra vez a Hartog. Su realismo es un realismo crítico en la medida en que, como hemos visto, se enfrenta con otros modelos realistas y denuncia este secuestro del porvenir, poniendo en tela de juicio la sintonía de los discursos dominantes con el presente y cuestionando la equivalencia o equiparación que implican entre la representación del mundo, la realidad social y los modos de producirla.

Termino citando un poema más, el último, un texto no menos crítico ni realista que los anteriores, no menos materialista ni prosaico. Se trata de unos versos del argentino Sergio Raimondi y de su libro Poesía civil (2001). Creo que resumen bastante bien el cambio que se ha producido en esta década tanto por lo que respecta a los vínculos del poeta con las tradiciones románticas y realistas como por lo que toca a la manera de intervenir políticamente a través de la descripción de los objetos como forma de aprehensión material del mundo. A la pregunta "¿Qué dice cierta poesía de los años noventa sobre la relación entre las palabras y las cosas?", una respuesta, compleja y completa, como para acabar, puede ser esta:

\section{¿Qué es el mar?}

El barrido de una red de arrastre a lo largo del lecho, mallas de apertura máxima, en el tanque setecientos mil litros de gas-oil, en la bodega bolsas de papa y cebolla, 
jornada de treinta y cinco horas, sueño de cuatro, café, acuerdos pactados en oficinas de Bruselas, crecimiento del calamar illex en relación a la temperatura del agua y las firmas de aprobación de la Corte Suprema, circuito de canales de acero inoxidable por donde el pescado cae, abadejo, hubbsi, transferencias de permiso amparadas por la Secretaría de Agricultura, Ganadería y Pesca; ahí: atraviesa el pesquero la línea imaginaria del paralelo, va tras una mancha en la pantalla del equipo de detección, ignorante el cardumen de la noción de millas o charteo, de las estadísticas irreales del INIDEP o el desfasaje entre jornal y costo de vida desde el año mil novecientos noventa y dos, filet de merluza de cola, SOMU y pez rata, cartas de crédito adulteradas, lámparas y asiático pabellón, irrupción de brotes de aftosa en rodeos británicos, hoki, retorno a lo más hondo de toneladas de pota muerta ante la aparición de langostino (valor cinco veces mayor), infraestructura de almacenamiento y frío, caladero, eso. (Raimondi 28)

\section{Obras citadas}

Augé, Marc. "De l'imaginaire au tout fictionnel". Recherches en Communication 7 (Paris, 1997): 105-120. Impreso.

Batista, León Félix. Se borra si es leído. Santo Domingo:

Consejo de la Cultura, 200o. Impreso.

Casas, Fabián. El salmón. Buenos Aires: Tierra Firme, 1996. Impreso.

Casas, Fabián. Oda. Buenos Aires: Tierra Firme, 2003. Impreso.

Fabre, Luis Felipe. Vida quieta. México: Alforja, 2000. Impreso.

Foster, Hal. The Return of the Real: the Avant-garde at the End of the Century. Boston: MIT, 1996. Impreso.

Freidemberg, Daniel. "Escuchar decir nada (una vieja respuesta nunca enviada y después notas, notas de las notas y algo más". Tres décadas de poesía argentina: 1976-2006. Ed. Jorge Fondebrider. Buenos Aires: Libros del Rojas, 2006. 143-184. Impreso.

Gambarotta, Martín. Punctum. Buenos Aires: Tierra Firme, 1996. Impreso. García Helder, Daniel. El guadal. Buenos Aires: Tierra Firme, 1994. Impreso. Guerrero Gustavo, ed. Cuerpo plural: antología de la poesía hispanoamericana contemporánea. Buenos Aires/Madrid/Valencia: Pre-Textos, 2010. Impreso. 
Hartog, Francois. Régimes d'historicité, présentisme et expériences du temps. Paris: Seuil, 2003. Impreso.

Huyssen, Andreas. Twilight Memories. New York: Routledge, 1995. Impreso.

Jaguaribe, Beatriz. O choque do real. Rio de Janeiro: Rocco, 2007. Impreso.

Ludmer, Josefina, ed. Las culturas de fin de siglo. Buenos Aires: Beatriz Viterbo, 1994.

Martín Barbero, Jesús. "Dislocaciones del tiempo y nuevas topografías de la memoria" 2000. Web. 24 de febrero de 2015.

Mazzoni, Ana y Damián Selci. "Poesía actual y cualquerización”. Tres décadas de poesía argentina: 1976-2006. Ed. Jorge Fondebrider. Buenos Aires: Libros del Rojas, 2006. 258-268. Impreso.

Mora, Vicente Luis. Pangea: internet, blogs y comunicación en un mundo nuevo. Sevilla: Fundación José Manuel Lara, 2006. Impreso.

Moreno Villamediana, Luis. Cantares digestos. Mérida: Mucuglifo, 1996. Impreso.

Moreno Villamediana, Luis. Manual para días críticos.

Caracas: Pequeña Venecia, 2001. Impreso.

Muniz, Vik. "Official webpage". Web. 24 de febrero de 2015.

Porrúa, Ana. "Lo nuevo en la poesía argentina de los 9o's". Foro Hispánico 24 (2003): 85-96. Impreso.

Prieto, Martín y Daniel García Helder. "Boceto $n^{\circ} 2$ para un... de la poesía argentina actual". Tres décadas de poesía argentina: 1976-2006. Ed. Jorge Fondebrider. Buenos Aires: Libros del Rojas, 2006. 101-116. Impreso.

Raimondi, Sergio. Poesía civil. Vox: Bahía Blanca, 2001. Impreso.

Rancière, Jacques. La parole muette, essai sur les contradictions de la littérature. Paris: Hachette, 1998. Impreso.

Rodríguez Sosa, Mariana. "Mujeres que hacen performances". Los grandes problemas de México VII: relaciones de género. Comps. Ana María Tepichin, Karine Tinat y Luzelene Gutiérrez. México: El Colegio de México, 2010. 156-189. Impreso.

Suazo, Félix. Panorámica del arte emergente venezolano.

Caracas: Fundación Telefónica, 2013. Impreso. 